Appeared as: K. Abraham, H. Mielke, W. Huisinga and U. Gundert-Remy 'Elevated Internal

Exposure of Children in Simulated Acute Inhalation of Volatile Organic Compounds: Effects of Concentration and Duration' ARCHIVES OF TOXICOLOGY 79 pp 63-73 (2005)

Klaus Abraham, Hans Mielke, Wilhelm Huisinga and Ursula Gundert-Remy

\title{
Elevated Internal Exposure of Children in Simulated Acute Inhalation of Volatile Organic Compounds: Effects of Concentration and Duration
}

Klaus Abraham, Hans Mielke, and Ursula Gundert-Remy

Federal Institute for Risk Assessment

Thielallee 88-92, 14195 Berlin, Germany

Wilhelm Huisinga

Department of Mathematics and Computer Science, Free University Berlin Arnimallee 2-6, 14195 Berlin, Germany

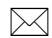

Klaus Abraham

Bundesinstitut für Risikobewertung

Thielallee 88-92, 14195 Berlin, Germany

email: k.abraham@bfr.bund.de

Tel.: +49-30-8412-3369, Fax.: +49-30-8412-3970 


\section{ABSTRACT}

When deriving health based exposure limits in recent years, attention has been drawn to susceptible subpopulations, in particular to children. We investigate the differences in kinetics between children and adults during inhalation of styrene as a typical category 3 volatile organic compound (VOC), i.e. a gas with a high rate of alveolar absorption (due to low reactivity and low water solubility). Internal exposure was simulated using a physiologically based kinetic model over a broad range of airborne concentrations ( 1 to 1000 ppm) and for an exposure time of up to eight hours according to the scenario in the acute exposure guideline level (AEGL) program. Age-specific anatomical and physiological parameters and compound-specific data were derived from the literature. The calculated concentrations in arterial blood are higher in children than in adults, and are highest in the newborn. For an 8-hour exposure to low concentrations, the calculated arterial concentration in the newborn is higher by a factor of 2.3 than in the adult. This is mainly due to the relatively high ventilation rate and the immature metabolism. With increasing airborne concentration, the ratio of arterial concentrations (newborn/adult) increases to a maximum of 3.8 at $130 \mathrm{ppm}$ in ambient air, and declines with further increments of concentration to a value of 1.7. This is because the metabolism of the newborn becomes non-linear at lower concentrations than in adults. At high concentrations, metabolism is saturated in both age groups. For shorter exposures, the dose-dependency of the concentration ratios (newborn/adult) is less pronounced. This is the first article to show that the intraspecies uncertainty factor may vary with concentration and duration of exposure.

Keywords: children, inhalation, kinetics, model, risk assessment, styrene

\section{Abbreviations:}

AEGL: acute exposure guideline level

VOC: volatile organic compound 


\section{INTRODUCTION}

Risk assessment paradigms have been refined over the years, and recently, increasing attention has been paid to sensitive subpopulations, in particular children. Exposure patterns have been considered in various age groups (Cohen Hubal et al. 2000). In addition, several authors have described age-dependent kinetics, which show lower metabolic elimination in the very young (Dourson et al. 2002, Ginsberg et al. 2004, Hattis et al. 2003, Renwick et al. 2000, Scheuplein et al. 2002).

A specific exposure scenario, namely the accidental release of industrial chemicals leading to an airborne exposure of the general population, requires risk assessment which includes the consideration of sensitive subpopulations. In this context, recent history also urges considering possible terrorist attacks with chemical warfare agents. Special programs exist, e.g. the US-EPA acute exposure guideline levels (AEGL) program, in which a series of health based airborne concentrations are derived to inform the risk managers. Whereas other programs are aimed at setting 'safe' levels, which are by definition below the no adverse effect level, acute exposure guideline levels cover a broad range of concentrations, related to varying degrees of health impairment. In the standing operating procedures for the development of AEGLs (US-AEGL committee, 2001), three levels are defined (AEGL 1: discomfort, AEGL 2: irreversible or other serious, long-lasting adverse effects, AEGL 3: lifethreatening effects or death) and several exposure times are considered (10 min, $30 \mathrm{~min}, 1$ $\mathrm{h}, 4 \mathrm{~h}$ and $8 \mathrm{~h})$.

Exposure of the general population includes that of sensitive subgroups who develop stronger effects (local or systemic) compared to the 'normal' population at the same external concentration. In sensitive subjects, higher systemic response may be due to toxicokinetic factors or to toxicodynamic factors. Toxicokinetic factors, e.g. higher uptake due to higher ventilation rates or reduced elimination rates, result in higher internal exposure, whereas a 
stronger response at the same level of internal exposure is indicative for a change in sensitivity due to toxicodynamic factors.

The aim of this article is to quantify differences in internal concentrations based on agespecific physiological parameters of uptake and of kinetics during inhalation exposure. We compared the internal concentrations of children in different age groups with the concentration of the 'reference man'. A physiologically based kinetic model was applied in which the body is described by several compartments representing organs (e.g. Ramsey and Andersen, 1984). It offers the opportunity to adapt the input parameters to the properties of the chemical (partitioning, metabolism) and to the age-dependent anatomical and physiological data. For adults, the predictions of such multi-compartment models were verified by measurements from exposure to industrial VOCs and from drugs used in anesthesia (e.g. Fiserova-Bergerova, 1983). Recently, this approach has been used to model age-dependent differences in toxicokinetics at low concentrations (Pelekis et al. 2001, Price et al. 2003, Sarangapani et al. 2003). We apply the approach in the context of AEGLs, where the relevant concentrations cover a broad range and where age-dependent differences in metabolic capacity also play a role.

\section{MODEL DESCRIPTION}

\section{Model structure}

A physiologically based kinetic model was used which describes the body as simplified system with seven compartments representing adipose tissue, muscle/skin, skeleton, brain, kidney, liver (with metabolic capacity characterized by $\mathrm{K}_{\mathrm{m}}$ and $\mathrm{V}_{\max }$ ), and the remainder as vessel rich organs (Figure 1). A comparable model structure is often used to simulate the kinetics of volatile organic compounds (e.g. Ramsey and Andersen, 1984). 


\section{Mathematical description}

In the model, the rhythmic process of breathing is simplified as continuous air stream to the alveolar region of the lungs ( $Q_{P}$, alveolar ventilation rate). During VOC exposure, the inhaled stream contains the substance at a certain concentration $\left(C_{I}\right)$ corresponding to the concentration in ambient air. It flows along the alveolar membrane where gas exchange takes place, and leaves the region with a changed concentration $C_{X}$ in exhaled air. On the other side of the membrane, venous blood with a flow corresponding to the cardiac output $Q_{C}$ and a VOC concentration $C_{V}$ enters the alveolar region and leaves it as arterial blood with a changed concentration $C_{A}$. The mass balance of the VOC in the lungs is described in the following equation:

$$
\text { Amount In }=Q_{P} \cdot C_{I}+Q_{C} \cdot C_{V}=Q_{P} \cdot C_{X}+Q_{C} \cdot C_{A}=\text { Amount Out }
$$

. The VOC diffusion is driven by the concentration gradient, and at the end of passing the alveolar region, the ratio of concentrations in arterial blood and in exhaled air has equilibrated to the blood:air partition coefficient $P_{B}=C_{A} / C_{X}$. Thus, the arterial concentration can be expressed as

$$
C_{A}=\frac{Q_{P} \cdot C_{I}+Q_{C} \cdot C_{V}}{Q_{C}+Q_{P} / P_{B}}
$$

VOCs entering the various organ/tissue groups via arterial blood are assumed to be distributed rapidly throughout the tissue volume. Let $C_{T}$ be the VOC concentration in tissue $T$, and $V_{T}$ the volume of tissue, then the change in $V_{T} \cdot C_{T}$, the amount of VOC in tissue $T$, is equal to the difference of the concentrations in blood flowing in $\left(C_{A}\right)$ and out $\left(C_{V T}\right)$ of the tissue, by the blood flow $Q_{T}$ through the tissue, and in metabolizing tissue also by the rate of elimination $R A M_{T}$.

$$
\begin{gathered}
V_{T} \frac{d}{d t} C_{T}=Q_{T} \cdot\left(C_{A}-C_{V T}\right) \text { in non-metabolizing tissue } \\
V_{T} \frac{d}{d t} C_{T}=Q_{T} \cdot\left(C_{A}-C_{V T}\right)-R A M_{T} \text { in metabolizing tissue (liver) }
\end{gathered}
$$


Elimination is assumed to occur only in the liver and is modeled via Michaelis-Menten kinetics with $V_{\max }$ being the maximum rate of elimination and $K_{m}$ the concentration (in venous liver blood) at which $V=\frac{1}{2} V_{\max }$.

$$
R A M_{L}=V_{\max } \cdot \frac{C_{L}}{P_{L} \cdot K_{m}+C_{L}}
$$

To account for age-related metabolic activity, $V_{\max }$ is scaled by liver size and by a metabolism factor for the newborn $\left(\mathrm{MF}_{\text {newb. }}\right)$ and the 1-year-old child $\left(\mathrm{MF}_{1 \mathrm{y}}\right)$ representing the age-related reduced amount of the enzyme involved in the metabolism of the particular chemical:

$$
V_{\max }=V_{\max a d u l t} \cdot \frac{V_{L}}{V_{L \text { adult }}} \cdot M F
$$

VOC concentration in venous blood leaving each tissue group $T$ is determined by a tissue:blood partition coefficient $P_{T}$.

$$
C_{V T}=\frac{C_{T}}{P_{T}}
$$

Before returning to the lungs, venous blood from all the tissue groups in the model is mixed.

$$
C_{V}=\frac{1}{Q_{C}} \sum_{T} Q_{T} \cdot C_{V T}
$$

In this model, the following assumptions are implicit: the gas has no local reactivity (category 3, US-EPA 1994), no 'wash in-wash out' phenomenon (Johanson 1991) in the airways, absorption exclusively in the alveoli, rapid gas exchange between alveolar air and capillary blood following the concentration gradient, and rapid distribution in tissue (well-mixed compartments). Blood flow from intestinal organs to the liver through the portal vein is simplified as direct blood flow to the liver. For the calculations we assumed constant concentrations in ambient air, and that the alveolar ventilation rate does not change during exposure (e.g. due to the exposure itself or due to physical activity). 


\section{Styrene as model compound}

Styrene has been selected for the model calculations, as a typical category 3 gas, with chemical-specific data available in the literature. Styrene partition coefficients were assumed to be age-independent. They were taken from Meulenberg and Vijverberg (2000) to be 55.6, 2.50, 57.3, 1.82, and 1.02 for blood:air, liver:blood, fat:blood, brain:blood, and kidney:blood, respectively. For the muscle/skin compartment, the reported partition coefficient of 1.29 for

muscle:blood was used. As for the remaining compartments (vessel rich group, skeleton) no values are given, the coefficient of the liver was used for these tissues as an approximation. Data sets for the activity of the main metabolizing enzyme (cytochrome P450 2E1, = CYP 2E1) were taken from Csanady et al. (1994): $\mathrm{V}_{\max }=0.002 \mathrm{mmol} / \mathrm{h}$ per g liver (corresponding to $375 \mathrm{mg} / \mathrm{h}$ in the adult with a liver weight of $1800 \mathrm{~g}$ ) and $\mathrm{K}_{\mathrm{m}}=0.01 \mathrm{mmol} / \mathrm{L}$ venous blood (1.04 mg/L). CYP 2E1 protein content in liver samples was reported to be about $14 \%$ of adult content in newborns ( 1 to 7 days old) and about 50\% in one-year-old children (Vieira et al.1996). For children aged 5 years and above, the CYP2E1 content per gram hepatic tissue was assumed to equal that of adults.

\section{Model calculations and sensitivity analysis}

For the model calculations, duration of exposure was limited to 8 hours, the maximum exposure duration considered in the AEGL scenario. A concentration range between 1 and 1000 ppm was investigated because this range would be representative for AEGL values (Voss, personal communication). The course of concentrations in arterial blood was simulated for adults and for the ages $0,1,5,10$ and 15 years. The aim of the study was to compare the toxicokinetics of styrene in children with that of the 'reference man' (middleaged healthy male adult). This is done by calculating the child to adult ratio of arterial concentrations for each age group. For all numerical computations, the Matlab software (The MathWorks, Natick, MA; Version 6.5.1) was used.

To determine the factors with major influence on the ratios of arterial concentrations, a sensitivity analysis was performed by calculating the ratio after changing each of the 27 
anatomical, physiological, and chemical-specific parameters by adding $20 \%$. The anatomy and physiology of the 'reference man' was not changed. Three concentration levels were analyzed ( $1 \mathrm{ppm}, 130 \mathrm{ppm}$, and $1000 \mathrm{ppm}$ ) with two different exposure times ( 1 hour and 8 hours). Note that the increase of blood flow to one compartment leads to a corresponding change in the cardiac output, and that the increase of the cardiac output leads to a corresponding change of blood flows to all organs and tissues.

\section{SELECTION OF AGE-DEPENDENT ANATOMICAL AND PHYSIOLOGICAL DATA}

To account for age-related differences, values of the anatomical and physiological parameters had to be determined for different age groups. The selection of tissue masses, alveolar ventilation rates, cardiac output and tissue blood flow rates would be straightforward, if data was available from simultaneous measurements of all the parameters in different age groups (healthy subjects) using the same methodological tools under resting conditions. However, in the absence of this information, different sources have been used to collate the relevant information. Where more than one set of data was found, the selection was made according to the following criteria: reliability of the method, healthy subjects, and resting conditions investigated. Studies in which a broad age range is covered were preferred over studies with only one age group. In this article, anatomical and physiological data of the middle-aged healthy male adult was taken to serve as the reference ('reference man'). For the other ages, we chose the newborn as well as the 1-, 5-, 10- and 15-year-old child. For the latter, values for the male were taken if available. The selected data is compiled in Table 1.

\section{Body and organ weights}

Data were taken from the recent ICRP report (2003). The mass of the vessel rich compartment was calculated as the sum of the masses of active bone marrow, adrenals, alimentary system, gall bladder wall, heart, pancreas, respiratory system (trachea, larynx, 
lung tissue), spleen, thymus, thyroid and tonsils. The mass of the skeleton given in the ICRP report was correspondingly reduced by the mass of active bone marrow. The remaining small organs (e.g. eyes and ureters) were felt to represent a negligible portion of the body mass. The mass of the blood is not considered in the model.

\section{Cardiac output}

Data for cardiac presented in the ICRP report (2003) lacks consistency with body weight and growth for very young children. Therefore, we used data of Alverson et al. (1987) obtained in 31 healthy children from repetitive measurements by noninvasive pulsed Doppler ultrasound during their first year of life. Left ventricular cardiac output was reported to be $210 \pm 44$ $\mathrm{mL} / \mathrm{kg} \cdot \mathrm{min}$ shortly after birth and $182 \pm 44 \mathrm{~mL} / \mathrm{kg} \cdot \mathrm{min}$ at the age of 1 year, corresponding to $44 \mathrm{~L} / \mathrm{h}$ (newborn, $3.5 \mathrm{~kg}$ ) and $109 \mathrm{~L} / \mathrm{h}(1$-year-old, $10.0 \mathrm{~kg})$. The authors had demonstrated a high correlation $(r=0.98)$ of their ultrasound technique with invasive measurements by heart catheterization in a population of similar age (Alverson et al. 1982). For children 5 years old and above, values for cardiac output were taken from ICRP (2003).

\section{Alveolar ventilation}

Alveolar ventilation is the proportion of the total pulmonary ventilation which reaches the alveoli (tidal volume minus physiological dead space, which is roughly one third of the tidal volume under resting conditions, independent of age: Kerr 1976; Polgar and Weng, 1979). There have been several studies for newborns using different measuring methods. The following results (mean values) were obtained under adequate conditions (gas volume at normal body temperature and ambient barometric pressure, saturated with water vapor). Data from Evans et al. 1977 (147 mL/kg.min, mean age 22 hours), Sandberg et al. 1984 (142 $\mathrm{mL} / \mathrm{kg} \cdot \mathrm{min}$, age 26 hours $)$, Nelson et al. $1962(169 \mathrm{~mL} / \mathrm{kg} \cdot \mathrm{min}$, age between of 26 hours to 3 days) and Lagneaux et al. 1988 (227 $\mathrm{mL} / \mathrm{kg} \cdot \mathrm{min}$, mean age 16 days) was assessed. We estimated an alveolar ventilation rate of $42 \mathrm{~L} / \mathrm{h}(200 \mathrm{~mL} / \mathrm{kg} \cdot \mathrm{min})$ for newborns, which is between the value reported by Lagneaux et al. and the other three authors. We took into 
consideration increasing basal oxygen consumption (Hill and Rahimtulla 1965) within the first three days of life (the period in which the three studies with low values of alveolar ventilation was performed) and the 2.5 -fold higher energy/oxygen expenditure in neonates as compared to adults, which directly corresponds to the ventilation rates (Layton 1993).

Data from infants ( $n=21$, age 0.5 to 8.5 months: Lees et al. 1967) was recalculated and extrapolated to the age of one year. The value of $128 \mathrm{~mL} / \mathrm{kg} \cdot \mathrm{min}(77 \mathrm{~L} / \mathrm{h})$ seems relatively low, probably due to measurements during cardiac catheterization (sleeping conditions). Using the basal metabolic rate in 1-year-old children reported to be 2.8 times higher than in newborns (ICRP 2003; see Table 1), a ventilation rate of $118 \mathrm{~L} / \mathrm{h}$ was calculated for the age of 1 year. Finally, the value of $109 \mathrm{~L} / \mathrm{h}$ was chosen, which is equal to the cardiac output and consistent with the ventilation rates for the older children. Using data from children and adolescents ( $n=72$, age 5 to 16 years: Kerr 1976) and the equation given $\left(Q_{P}[L / \mathrm{min}]=0.034\right.$ · Height $[\mathrm{cm}]+0.395)$, alveolar ventilation rates of $246 \mathrm{~L} / \mathrm{h}, 305 \mathrm{~L} / \mathrm{h}$ and $364 \mathrm{~L} / \mathrm{h}$ were calculated for the 5-, 10- and 15-year-old children, respectively. These values correspond well to those of the cardiac output for the 10- and 15-year old child, but the value of $246 \mathrm{~L} / \mathrm{h}$ for the 5-year-old one seems relatively high compared to the cardiac output (204 L/h) and to the metabolic rate from ICRP (2003). Therefore, a value of $210 \mathrm{~L} / \mathrm{h}$ has been estimated based on the ventilation rate in the 1-year-old child and on the ratio of metabolic rates. For the typical male adult, an alveolar ventilation rate of $390 \mathrm{~L} / \mathrm{h}$ was chosen, corresponding to the cardiac output and the increase of the basal metabolic rate from 15 years to adulthood.

\section{Blood flow to organs and tissues}

Blood flow rates as percentage of cardiac output are given in the ICRP report (ICRP 2003) for the resting middle-aged male adult, based on a compilation of published data by Williams and Leggett (1989) and Leggett and Williams (1995). These data were used to calculate blood flow rates (L/h) for liver (arterial and portal flow), brain, kidney, adipose tissue (fat), muscle/skin and skeleton (without active bone marrow). For the vessel rich organs, blood flow rates were reported for active bone marrow, adrenals, heart, pancreas, spleen and 
thyroid, but not for the remaining organs of this group (alimentary system, respiratory system including lungs, thymus and tonsils). We decided to allocate the difference between cardiac output $(390 \mathrm{~L} / \mathrm{h})$ and the sum of the blood flows to organs/tissues $(333 \mathrm{~L} / \mathrm{h})$ to the group of the vessel rich organs.

Values for blood flow to the brain were taken from a study in children and young adults ( $n=42$, age 2 days to 22 years: Chiron et al. 1992) using SPECT with ${ }^{133} X e$. These values are in accordance with those from Schöning and Hartig (1996) using sonography, and the value for the 19 years-old adult is in agreement with that of the ICRP report for the male adult. For the kidney, specific blood flows measured by Doppler duplex sonography were reported to be $410 \pm 120 \mathrm{~mL} / \mathrm{min}$ per $100 \mathrm{~g}$ kidney independent of age $(n=62$, age 1 to 16 years:

Grunert et al. 1990). The mean value matches well that of $398 \mathrm{~mL} / \mathrm{min}$ per $100 \mathrm{~g}$ kidney calculated from the ICRP report for male adults. In newborns, renal blood flow was calculated as a fraction of cardiac output (16.1 $\pm 3.7 \%$, Visser et al. 1992), resulting in a mean value of $472 \mathrm{~mL} / \mathrm{min}$ per $100 \mathrm{~g}$ kidney.

For the remaining five compartments (liver, adipose tissue, muscle/skin, vessel rich group and skeleton), there are few or no reports on blood flows in children. The following approach was chosen to bridge the data gap. First, specific blood flow rates (perfusion per gram tissue) were calculated from data in the ICRP Report (2003) for the male adult. These values were multiplied by the organ/tissue masses of the specific age in children to result in (preliminary) age-specific blood flow rates, assuming the relative flows of these five compartments to be equal to those in adults. As expected, for all age groups the resulting sum of tissue flows (brain, kidney and five remaining compartments) is lower than the cardiac output, as specific blood flow values are usually higher in children than in adults. This reflects the higher energy expenditure due to growth and higher body surface/weight ratio. In order to adjust the sum of all organ blood flows to the total cardiac output, normalization factors were calculated for each age group (see Table 1), which were then used to scale up the preliminary blood flows 
of the five compartments (all except brain and kidney) so that the sum of all blood flows (including brain and kidney) equals the cardiac output.

\section{RESULTS}

\section{Styrene concentrations in arterial blood}

The concentration of styrene in the arterial blood increased with duration of exposure and did not reach steady state within the 8-hour exposure period for all concentrations in the investigated range between 1 and 1000 ppm. As expected, arterial concentrations decrease after cessation of exposure. Figures 2a, 3a and 4a demonstrate the results for 1, 100 and 1000 ppm, respectively. In the newborn, the arterial concentrations are distinctly higher than in all other age groups. The concentration-time profile of the 1-year-old child can also be distinguished from the other profiles at 1 and $100 \mathrm{ppm}$. With increasing age, the profile became increasingly similar to that of the adult, with only small differences for the 15 -yearold child.

\section{Ratios of arterial concentrations (child/adult)}

The ratios of the arterial concentrations are shown in Figure $2 b, 3 b$, and $4 b$ for styrene concentrations in ambient air of 1, 100 and 1000 ppm, respectively. They reveal dose- and duration-dependence: in the newborn, the ratio reaches a maximum value of 2.3 after an exposure duration of about 1 hour at 1 ppm in ambient air (Figure 2b). For the other age groups, the maximum ratios are 1.5, 1.35, 1.25, and 1.2 for the 1-, 5-, 10- and 15-year-old child, respectively, reached after about 30 minutes. At 100 ppm in ambient air, in the newborn, the ratio has reached a value of 3.8 after 8 hours (Figure 3b). At 1000 ppm, the pattern for all age groups is similar to that at $1 \mathrm{ppm}$, with maximum ratios reached after a short duration of exposure. 
In Figure 5, the ratio is shown to depend on the styrene concentration in ambient air (values for 8 hour exposure). The maximum ratio of 3.8 is calculated for the newborn exposed at 130 ppm. With increasing age, the maximum ratios become lower and occur at higher concentrations in ambient air. In the 15-year-old child, the maximum ratio is about 1.3 at an exposure to $300 \mathrm{ppm}$.

As the highest values were calculated for the newborn, further calculations were performed in this age group in order to describe the complex relationship between the concentration ratio (newborn/adult) influenced by the external styrene concentration in the ambient air and the duration of exposure. The results are presented in a three dimensional graph (Figure 6a, with additional plan view: Figure 6b; note the logarithmic scale). As can be seen, exposure duration up to 1 hour resulted in concentration ratios lower than 2.5 independent of the ambient air concentration. For longer duration of exposure, the ratios increase continuously with increasing concentrations in the ambient air, reaching a maximum value at about 130 ppm. With higher concentrations, the concentration ratios become lower. The plan view provides the best description of the exposure conditions in terms of duration and concentration in ambient air. The worst conditions for the newborn can be seen in terms of the most pronounced difference to the adult (red area: ratios higher than 3.0).

\section{Sensitivity analysis of the concentration ratio (newborn/adult)}

As the child-to-adult ratio of the concentration time profiles turned out to depend both on exposure time and concentration in the ambient air, a local sensitivity analysis for the newborn was performed for three concentrations and for two s. In Table 2, those parameters are compiled whose $20 \%$ increase changes the ratio (positively or negatively) by more than $1 \%$. When considering anatomical and physiological parameters, only those of the newborn were changed. For any exposure duration and for all concentrations, the alveolar ventilation rate $\left(Q_{P}\right)$ has the highest impact on the ratios, increasing them with increasing values. Regarding the blood flow rates, that of adipose tissue $\left(Q_{F}\right)$ is an important factor leading to lower ratios, and the results for the increased cardiac output $\left(Q_{C}\right)$ mainly reflect the 
corresponding increase of $Q_{F}$ (and the increase of $Q_{L}$, see below). The third group of sensitive parameters determines metabolism: $V_{\max }, \mathrm{K}_{\mathrm{m}}$, the liver:blood partition coefficient $\left(P_{L}\right)$, the metabolism factor for the newborn $\left(\mathrm{MF}_{\text {newb }}\right)$ and the newborn's liver volume $\left(\mathrm{V}_{\mathrm{L}}\right)$. The two last mentioned factors have equal influence on the newborn's $V_{\max }$ which is important for the exposure at $1 \mathrm{ppm}$, but not at $1000 \mathrm{ppm}$. Alteration of $\mathrm{V}_{\max }$ (in newborn and adult) lowers the ratio at $1 \mathrm{ppm}$ and increases it at the higher concentrations of 130 and 1000 ppm. $\mathrm{K}_{\mathrm{m}}$ is an influential factor for $1 \mathrm{ppm}$ (higher ratios) and $130 \mathrm{ppm}$ (lower ratios). The blood flow to the liver $\left(Q_{\mathrm{L}}\right)$ is a relevant parameter exclusively for the low concentration of 1 ppm.

\section{DISCUSSION}

This is the first article showing that toxicokinetic differences between children and adults are not only age-dependent but also depend on the level of external exposure and the exposure time. A model approach was used to quantify the differences for styrene, a typical class 3 VOC. In order to conform with the US-EPA AEGL scenario, exposure duration was chosen to be up to eight hours, and exposure levels cover a wide range of concentrations (between 1 ppm and $1000 \mathrm{ppm}$ ). The ratio of arterial concentrations (child/adult) has been selected as an appropriate comparison of the concentration in the 'typical' child of a certain age to that in the 'reference man'. As the acute (neuro)toxicity of styrene is supposed to be due to the parent compound (Pierce et al. 1998), metabolites were not considered. The model we used has seven compartments and is a modification of the Ramsey and Andersen model (1984) for styrene. The modifications have been made in order to represent age-related differences in relative organ weights and organ flow rates (for example, the brain represents nearly $11 \%$ of the body weight in the newborn, but only $2 \%$ in the adult). Johanson (1991) added a 'wash in-wash out' process to the model which describes the pre-alveolar epithelial disposition of the chemical during inhalation leading to lower alveolar concentrations than in ambient air, and to re-diffusion during exhalation. This is applicable in particular to solvents 
with high water solubility. For styrene as a typical category 3 gas with lipophilic properties, it is generally accepted that this phenomenon plays a minor role.

Age-related anatomical and physiological data are most important when modeling agespecific differences in kinetics. From the process of selecting and estimating the data, uncertainty seems to be highest for the blood flow rates to organs/tissues. However, as the sensitivity analysis demonstrates, the influence of blood flow rates on the concentration ratios (newborn/adult) is irrelevant, with the notable exception of the blood flow to adipose tissue $\left(Q_{F}\right)$ and the blood flow to the liver $\left(Q_{L}\right)$ (Table 2). $Q_{F}$ plays a relatively important role during distribution within the first hours of exposure (large storage capacity of adipose tissue in case of styrene). $Q_{L}$ 's influence on the ratio is restricted to low concentrations in ambient air (1 ppm) where the metabolism of styrene is flow-limited.

Of all physiological parameters, the alveolar ventilation rate is the main factor responsible for the age-dependent higher internal exposure of children during inhalation. This is more or less independent of the concentration in ambient air and the duration of exposure (Table 2). The second important factor is the immature metabolism after birth, though not at very high concentrations when metabolism is saturated in both children and adults (see below). This is underlined by an additional calculation: setting the alveolar ventilation rate of the newborn to 18.7 L/h (instead of $42 \mathrm{~L} / \mathrm{h}$, = alveolar ventilation equal to that in the adult on a body weight basis), and the metabolism factor to 1.0 (mature metabolism), the calculated concentration ratios (newborn/adult) of Figure 6 would be between 0.45 and 0.8 . These values lower than 1.0 result from higher circulation rates (leading to faster distribution) and higher liver weight on a body weight basis in the newborn.

The parameters $\mathrm{V}_{\max }, \mathrm{K}_{\mathrm{m}}, \mathrm{P}_{\mathrm{L}}, \mathrm{MF}_{\text {newb }}$, and $\mathrm{V}_{\mathrm{L}}$ characterizing the metabolism also play an important role in determining the level of internal exposure (Table 2). Values for $V_{\max }$ and $K_{m}$ were taken from Csanady et al. (1994) who estimated them from measured blood concentrations in experimentally exposed human volunteers. Alternatively, blood 
measurements from rats can be 'scaled up', as done by Ramsey and Andersen (1984). Using this method, $\mathrm{V}_{\max }$ and $\mathrm{K}_{\mathrm{m}}$ are calculated to be $169 \mathrm{mg} / \mathrm{h}$ and $0.36 \mathrm{mg} / \mathrm{L}$, respectively, for a 73-kg 'reference man' (instead of $375 \mathrm{mg} / \mathrm{h}$ and $1.04 \mathrm{mg} / \mathrm{L}$, as given by Csanady et al. 1994). Using these lower values, the maximum of the concentration ratio (newborn/adult) after an 8-hour exposure is 3.9 (instead of 3.8) which is not markedly different, but it occurs at a concentration of $60 \mathrm{ppm}$ in ambient air (instead of $130 \mathrm{ppm}$ ).

Generally, the phenomenon of a dose-dependent maximum of the concentration ratios child to adult (Figure 5, 'crest' in Figure 6a) results from saturation of metabolism. While at low concentrations the metabolism depends on hepatic blood flow, it becomes saturated with higher inhalation exposure. In children, the proportion of saturation is higher due to higher internal exposure, which again leads to higher concentrations. The phenomenon is marked in young children due to their immature metabolism. With inhalation of even higher concentrations, metabolism is capacity-limited in all age groups and in the adult, and plays a minor role for determining internal concentrations. As a consequence, the child/adult ratios diminish.

In recent years, interest has grown in the susceptibility of children towards environmental chemicals. Lower metabolism rates in the very young have been reported by several authors (Cresteil 1998, Hattis et al. 2003). Pelekis et al. (2001) and, more recently, Price et al. (2003) and Sarangapani et al. (2003) have presented derivations of the adult to child kinetic uncertainty factors for inhalation exposure, based on physiological models. The ratios reported for styrene concentrations of $1 \mathrm{ppm}$ by Sarangapani et al. (2003) in the 1-month-old (1.95) and the 1-year-old infant (1.49) match well with the results we obtained (2.61 for the newborn and 1.41 for the 1-year-old child). However, as they restricted their calculations to the low concentration and steady state conditions, they did not observe the ratio's dependency on concentration and duration, which is important in case of acute exposure to high concentrations in ambient air. 


\section{Conclusion}

Our model simulations revealed that the concentration ratios (child/adult) are the result of a complex interaction of different factors: 1. age-related differences in physiological and anatomical parameters, 2. the physicochemical properties of the chemical, 3. the duration of exposure, and 4. the concentration in ambient air. If specific partition coefficients and metabolic constants are known for a chemical, a physiologically based model can be used to quantify the expected kinetic differences for a specific exposure situation. In risk assessment, e.g. in deriving acute exposure guideline levels (AEGLs), the concentration ratios (child/adult) calculated can be used to establish intraspecies assessment factors to account for kinetic differences between children and adults. In cases where chemical-specific data is not available, the default factor of 3.2 is often applied to considertoxicokinetic differences within the human population (Dourson et al. 2002, Hattis et al. 2003). This factor has to be reconsidered: in some cases, a higher factor may be more appropriate to cover highly susceptible populations, such as the newborn.

\section{Acknowledgements}

Supported by European Union (contract No. EVG1-CT-2002-00071) within $5^{\text {th }}$ Framework programme, and supported by Deutsche Forschungsgemeinschaft (DFG) as a project within DFG Research Center "Mathematics for key technologies", Berlin, Germany. 


\section{REFERENCES}

Alverson DC, Aldrich M, Angelus P, Backstrom C, Werner S (1987) Longitudinal trends in left ventricular cardiac output in healthy infants in the first year of life. J Ultrasound Med $6: 519-524$

Alverson DC, Eldridge M, Dillon T, Yabek SM, Berman W (1982) Noninvasive pulsed Doppler determination of cardiac output in neonates and children. J Pediatr 101:46-50

Chiron C, Raynaud C, Maziere B, Zilbovicius M, Laflamme L, Masure MC, Dulac O, Bourguignon M, Syrota A (1992) Changes in regional cerebral blood flow during brain maturation in children and adolescents. J Nucl Med 33:696-703

Cohen Hubal EA, Sheldon LS, Burke JM, McCurdy TR, Berry MR, Rigas ML, Zartarian VG, Freeman NC (2000) Children's exposure assessment: a review of factors influencing Children's exposure, and the data available to characterize and assess that exposure. Environ Health Perspect 108:475-486

Cresteil T (1998) Onset of xenobiotic metabolism in children: toxicological implications. Food Addit Contam 15 Suppl:45-51

Csanady GA, Mendrala AL, Nolan RJ, Filser JG (1994) A physiologic pharmacokinetic model for styrene and styrene-7,8-oxide in mouse, rat and man. Arch Toxicol 68:143-157

Dourson M, Charnley G, Scheuplein R (2002) Differential sensitivity of children and adults to chemical toxicity. II. Risk and regulation. Regul Toxicol Pharmacol 35:448-467

Evans JM, Hogg MI, Rosen M (1977) Measurement of carbon dioxide output, alveolar carbon dioxide concentration and alveolar ventilation in the neonate. $\mathrm{Br} \mathrm{J}$ Anaesth 49:453456

Fiserova-Bergerova V (1983) Modeling of inhalation exposure to vapors: Uptake, distribution, and elimination. Vol I and II, CRC Press, Boca Raton

Ginsberg G, Slikker W Jr, Bruckner J, Sonawane B (2004) Incorporating children's toxicokinetics into a risk framework. Environ Health Perspect 112:272-83

Grunert D, Schoning M, Rosendahl W (1990) Renal blood flow and flow velocity in children and adolescents: duplex Doppler evaluation. Eur J Pediatr 149:287-292 
Hattis D, Ginsberg G, Sonawane B, Smolenski S, Russ A, Kozlak M, Goble R (2003)

Differences in pharmacokinetics between children and adults - II. Children's variability in drug elimination half-lives and in some parameters needed for physiologicallybased pharmacokinetic modeling. Risk Anal 23:117-142

Hill JR, Rahimtulla KA (1965) Heat ballance and the metabolic rate of newborn babies. J Physiolo 180:239-265

ICRP Publication 89 (2003) Basic Anatomical and Physiological Data for Use in Radiological Protection: Reference Values. Elsevier Science Ltd, Oxford Johanson G (1991) Modelling of respiratory exchange of polar solvents. Ann Occup Hyg 35:323-339

Kerr AA (1976) Dead space ventilation in normal children and children with obstructive airways disease. Thorax 31:63-9

Lagneaux D, Mossay C, Geubelle F, Christiaens G (1988) Alveolar data in healthy, awake neonates during spontaneous ventilation: a preliminary investigation. Pediatr Pulmonol 5:225-231

Layton DW (1993) Metabolically consistent breathing rates for use in dose assessments. Health Phys 64:23-36

Lees MH, Way RC, Ross BB (1967) Ventilation and respiratory gas transfer of infants with increased pulmonary blood flow. Pediatrics 40:259-271

Leggett RW, Williams LR (1995) A proposed blood circulation model for Reference Man. Health Phys 69:187-201

Meulenberg CJ, Vijverberg HP (2000) Empirical relations predicting human and rat tissue:air partition coefficients of volatile organic compounds. Toxicol Appl Pharmacol 165:206216

Nelson NM, Prod'hom LS, Cherry RB, Lipsitz PJ, Smith CA (1962) Pulmonary function in the newborn infant. I. Methods: Ventilation and gaseous metabolism. Pediatrics 30:963974 
Pelekis M, Gephart LA, Lerman SE (2001) Physiological-model-based derivation of the adult and child pharmacokinetic intraspecies uncertainty factors for volatile organic compounds. Regul Toxicol Pharmacol 33:12-20

Pierce CH, Becker CE, Tozer TN, Owen DJ, So Y (1998) Modeling the acute neurotoxicity of styrene. J Occup Environ Med 40:230-240.

Polgar G, Weng TR (1979) The functional development of the respiratory system. From the period of gestation to adulthood. Am Rev Respir Dis 120:625-695

Price K, Haddad S, Krishnan K (2003) Physiological modeling of age-specific changes in the pharmacokinetics of organic chemicals in children. J Toxicol Environ Health A 66:417433

Ramsey JC, Andersen ME (1984) A physiologically based description of the inhalation pharmacokinetics of styrene in rats and humans. Toxicol Appl Pharmacol 73:159-175

Renwick AG, Dorne JL, Walton K (2000) An analysis of the need for an additional uncertainty factor for infants and children. Regul Toxicol Pharmacol 31:286-296

Sandberg K, Sjoqvist BA, Hjalmarson O, Olsson T (1984) Analysis of alveolar ventilation in the newborn. Arch Dis Child 59:542-547

Sarangapani R, Gentry PR, Covington TR, Teeguarden JG, Clewell HJ (2003) Evaluation of the potential impact of age- and gender-specific lung morphology and ventilation rate on the dosimetry of vapors. Inhal Toxicol 15:987-1016

Scheuplein R, Charnley G, Dourson M (2002) Differential sensitivity of children and adults to chemical toxicity. I. Biological basis. Regul Toxicol Pharmacol 35:429-447

Schöning M, Hartig B (1996) Age dependence of total cerebral blood flow volume from childhood to adulthood. J Cereb Blood Flow Metab 16:827-833

US-AEGL committee (2001) Standing operating procedures for developing acute exposure guideline levels for hazardous chemicals. National Academy Press, Washington DC

US-EPA (1994) Methods for derivation of inhalation reference concentrations and application of inhalation dosimetry (Doc.no. EPA/600/8-90/066F). Research Triangle Park, North Carolina 
Vieira I, Sonnier M, Cresteil T (1996) Developmental expression of CYP2E1 in the human liver. Hypermethylation control of gene expression during the neonatal period. Eur $\mathrm{J}$ Biochem 238:476-483

Visser MO, Leighton JO, van de Bor M, Walther FJ (1992) Renal blood flow in neonates: quantification with color flow and pulsed Doppler US. Radiology 183:441-444

Williams LR, Leggett RW (1989) Reference values for resting blood flow to organs of man. Clin Phys Physiol Meas 10:187-217 
Table 1 Anatomical and physiological data used for the simulation model. Data of children of different age and for the healthy, male adult ('reference man') under resting conditions (for sources: see text. Bold parameters: used directly for the model; other parameters are displayed as additional information for interpretation).

\begin{tabular}{|c|c|c|c|c|c|c|}
\hline Age & newborn & $1 \mathrm{y}$ & $5 y$ & $10 y$ & male $15 \mathrm{y}$ & male adult \\
\hline Body weight $^{\text {a }}(\mathbf{k g})$ & 3.5 & 10.0 & 19.0 & 32.0 & 56.0 & 73.0 \\
\hline Body height $^{\text {a }}(\mathrm{cm})$ & 51 & 76 & 109 & 138 & 167 & 176 \\
\hline Body surface Area ${ }^{a}\left(m^{2}\right)$ & 0.24 & 0.48 & 0.78 & 1.12 & 1.62 & 1.90 \\
\hline $\mathrm{BMR}^{\mathrm{a}}(\mathrm{kcal} / \mathrm{h})$ & 8.5 & 24.0 & 45.0 & 53.0 & 63.0 & 68.0 \\
\hline BMR (kcal/kg.h) & 2.43 & 2.40 & 2.37 & 1.66 & 1.13 & 0.93 \\
\hline Alveolar ventilation $Q_{P}(L / h)$ & 42 & 109 & 210 & 305 & 364 & 390 \\
\hline Qp. per kg bw (L/kg.h) & 12.0 & 10.9 & 11.1 & 9.5 & 6.5 & 5.3 \\
\hline Cardiac Output (L/h) & 44 & 109 & 204 & 300 & 366 & 390 \\
\hline \multicolumn{7}{|l|}{ Organ weights ${ }^{a}\left(g^{b}\right)$} \\
\hline Blood & 290 & 530 & 1500 & 2500 & 4800 & 5600 \\
\hline Adipose tissue & 930 & 3800 & 5500 & 8600 & 12000 & 18200 \\
\hline Liver & 130 & 330 & 570 & 830 & 1300 & 1800 \\
\hline Brain & 380 & 950 & 1310 & 1400 & 1420 & 1450 \\
\hline Kidney & 25 & 70 & 110 & 180 & 250 & 310 \\
\hline Muscle, skin & 975 & 2250 & 6170 & 11820 & 26000 & 32300 \\
\hline Other Vessel rich organs & 204 & 566 & 1141 & 1958 & 3071 & 3768 \\
\hline Skeleton (without act. marrow) & 320 & 1020 & 2090 & 3870 & 6870 & 9330 \\
\hline Sum of organ weights (g) & 3254 & 9516 & 18391 & 31158 & 55711 & 72758 \\
\hline Rel. liver mass (g/kg) & 37 & 33 & 30 & 26 & 23 & 25 \\
\hline Rel. mass of adip.tiss. $(\mathrm{g} / \mathrm{kg})$ & 266 & 380 & 289 & 269 & 214 & 249 \\
\hline Metabolism factor & 0.14 & 0.50 & 1 & 1 & 1 & 1 \\
\hline Normalization factor blood flow & 2.23 & 1.92 & 2.10 & 2.12 & 1.58 & 1.00 \\
\hline \multicolumn{7}{|l|}{ Blood flow rates $(L / h)$} \\
\hline Adipose tissue & 1.7 & 6.1 & 9.7 & 15.3 & 16.0 & 19.5 \\
\hline Brain & 11.4 & 33.6 & 55.8 & 57.1 & 48.6 & 46.8 \\
\hline Kidney & 7.1 & 17.2 & 27.1 & 44.3 & 61.5 & 74.1 \\
\hline Muscle, skin & 5.0 & 9.7 & 26.7 & 49.9 & 83.0 & 85.8 \\
\hline Vessel rich group & 5.7 & 13.5 & 29.8 & 51.6 & 60.4 & 56.5 \\
\hline Skeleton & 0.5 & 1.3 & 2.9 & 5.4 & 7.1 & 7.8 \\
\hline Liver & 12.6 & 27.5 & 52.0 & 76.4 & 89.4 & 99.5 \\
\hline Rel. hepatic blood flow (L/kg.h) & 3.6 & 2.8 & 2.7 & 2.4 & 1.6 & 1.4 \\
\hline
\end{tabular}

${ }^{a}$ from ICRP 2003

${ }^{\mathrm{b}}$ specific weight of 1.0 assumed for the model calculations 
Table 2 Sensitivity analysis of the ratio of arterial concentrations (newborn/adult) for three different concentrations of styrene in ambient air with a duration of 1 hour and 8 hours, respectively. A single change of $+20 \%$ for each parameter was simulated (for the anatomical and physiological parameters, only those of the newborn were changed). For each concentration, those parameters with an impact on the concentration ratio higher than $1 \%$ are listed in descending order, with the amount of relative change given in parentheses. The calculations were made for all 27 model parameters: $V_{\max }\left(=V_{\max \text { adult }}\right.$ in equation $\left.2 \mathrm{~d}\right)$ and the factor defining the enzyme immaturity in newborn $\left(M F_{\text {newb }}\right), K_{m}, 8$ partition coefficients $\left(P_{\text {Tissue }}\right), 7$ flow rates to organs/tissues $\left(Q_{T \text { Tissue }}\right.$ which correspondingly increase of $\left.Q_{C}\right), 7$ organ/tissue volumes, $Q_{P}$ and $Q_{C}$ (all flow rates to organs/tissues increased by $20 \%)$. For abbreviations of organs/tissues see Figure 1.

duration of exposure: 1 hour

\begin{tabular}{lll}
1 ppm & 130 ppm $^{\mathrm{a}}$ & $\mathbf{1 0 0 0} \mathbf{p p m}$ \\
\hline$Q_{P}(+15.1 \%)$ & $\mathrm{Q}_{\mathrm{P}}(+15.9 \%)$ & $\mathrm{Q}_{\mathrm{P}}(+14.8 \%)$ \\
$\mathrm{Q}_{\mathrm{C}}(-6.2 \%)$ & $\mathrm{Q}_{\mathrm{C}}(-6.8 \%)$ & $\mathrm{Q}_{\mathrm{C}}(-6.9 \%)$ \\
$\mathrm{V}_{\mathrm{L}}(-5.7 \%)$ & $\mathrm{Q}_{\mathrm{F}}(-5.7 \%)$ & $\mathrm{Q}_{\mathrm{F}}(-5.7 \%)$ \\
$\mathrm{MF}_{\text {newb }}(-5.4 \%)$ & $\mathrm{V}_{\mathrm{MS}}(-3.8 \%)$ & $\mathrm{V}_{\max }(+4.2 \%)$ \\
$\mathrm{Q}_{\mathrm{F}}(-4.3 \%)$ & $\mathrm{V}_{\mathrm{L}}(-3.6 \%)$ & $\mathrm{V}_{\mathrm{MS}}(-3.9 \%)$ \\
$\mathrm{P}_{\mathrm{L}}(-3.5 \%)$ & $\mathrm{MF}_{\text {newb }}(-2.6 \%)$ & $\mathrm{V}_{\mathrm{Br}}(-2.6 \%)$ \\
$\mathrm{V}_{\max }(-3.3 \%)$ & $\mathrm{V}_{\mathrm{Br}}(-2.4 \%)$ & $\mathrm{P}_{\mathrm{Br}}(+2.0 \%)$ \\
$\mathrm{V}_{\mathrm{MS}}(-2.7 \%)$ & $\mathrm{P}_{\mathrm{Br}}(-2.2 \%)$ & $\mathrm{V}_{\mathrm{VR}}(-1.9 \%)$ \\
$\mathrm{K}_{\mathrm{m}}(+2.6 \%)$ & $\mathrm{K}_{\mathrm{m}}(-2.0 \%)$ & $\mathrm{V}_{\mathrm{L}}(-1.6 \%)$ \\
$\mathrm{Q}_{\mathrm{L}}(-1.5 \%)$ & $\mathrm{V}_{\mathrm{VR}}(-1.8 \%)$ & \\
$\mathrm{V}_{\mathrm{Br}}(-1.4 \%)$ & $\mathrm{P}_{\mathrm{B}}(+1.3 \%)$ & \\
$\mathrm{P}_{\mathrm{Br}}(+1.2 \%)$ & & \\
$\mathrm{V}_{\mathrm{VR}}(-1.1 \%)$ & & \\
\end{tabular}

duration of exposure: 8 hours

\begin{tabular}{|c|c|c|}
\hline $1 \mathrm{ppm}$ & 130 ppm $^{\mathrm{a}}$ & 1000 ppm \\
\hline$Q_{P}(+14.3 \%)$ & $Q_{P}(+13.6 \%)$ & $Q_{P}(+11.7 \%)$ \\
\hline$V_{L}(-8.5 \%)$ & $Q_{F}(-9.6 \%)$ & $Q_{F}(-9.8 \%)$ \\
\hline $\mathrm{MF}_{\text {newb }}(-8.4 \%)$ & $Q_{c}(-9.4 \%)$ & $Q_{C}(-9.6 \%)$ \\
\hline$Q_{C}(-6.4 \%)$ & $\mathrm{K}_{\mathrm{m}}(-3.8 \%)$ & $\mathrm{V}_{\max }(+5.1 \%)$ \\
\hline$V_{\max }(-5.5 \%)$ & $\mathrm{P}_{\mathrm{B}}(+3.7 \%)$ & $\mathrm{P}_{\mathrm{MS}}(+1.7)$ \\
\hline$P_{L}(-5.3 \%)$ & $V_{L}(-3.5 \%)$ & $\mathrm{P}_{\mathrm{B}}(+1.7 \%)$ \\
\hline $\mathrm{K}_{\mathrm{m}}(+4.4 \%)$ & $\mathrm{MF}_{\text {newb }}(-3.4 \%)$ & $V_{F}(-1.6 \%)$ \\
\hline$Q_{F}(-4.3 \%)$ & $P_{L}(+3.3 \%)$ & \\
\hline$Q_{L}(-2.1 \%)$ & $\mathrm{V}_{\max }(+2.6 \%)$ & \\
\hline $\mathrm{P}_{\mathrm{B}}(+1.4 \%)$ & $V_{F}(-1.6 \%)$ & \\
\hline$V_{F}(-1.0 \%)$ & $P_{F}(-1.2 \%)$ & \\
\hline
\end{tabular}

a $130 \mathrm{ppm}$ is the maximum of the ratios of arterial concentrations (newborn/adult) after 8-hour exposure (see Figures 5 and 6 ). 


\section{Figure legends}

\section{Figure 1}

Diagram of the kinetic simulation model, including parameter abbreviations used.

\section{Figure 2, 3 and 4}

Model calculations for the inhalation exposure to styrene, with concentrations in ambient air of 1 ppm (Figure 2), 100 ppm (Figure 3) and 1000 ppm (Figure 4).

a: Concentration-time profile in arterial blood during styrene exposure for 8 hours and the following 8 hours in children (newborn, 1-, 5-, 10- and 15-year-old) and the adult.

b: corresponding ratios of arterial concentrations (child/adult) during the 8-hour exposure.

\section{Figure 5}

Ratios of arterial concentrations (child/adult) after a styrene exposure duration of 8 hours, depending on the concentration in ambient air, in children of different ages (newborn, 1-, 5-, 10- and 15-year-old).

\section{Figure 6}

Ratios of arterial concentrations (newborn/adult), depending in the duration of exposure ( 0 to 8 hours) and the styrene concentration in ambient air (note the logarithmic scale). Figure 6a shows the results as three dimensional graph, Figure $6 \mathrm{~b}$ shows the plan view. 
Figure 1

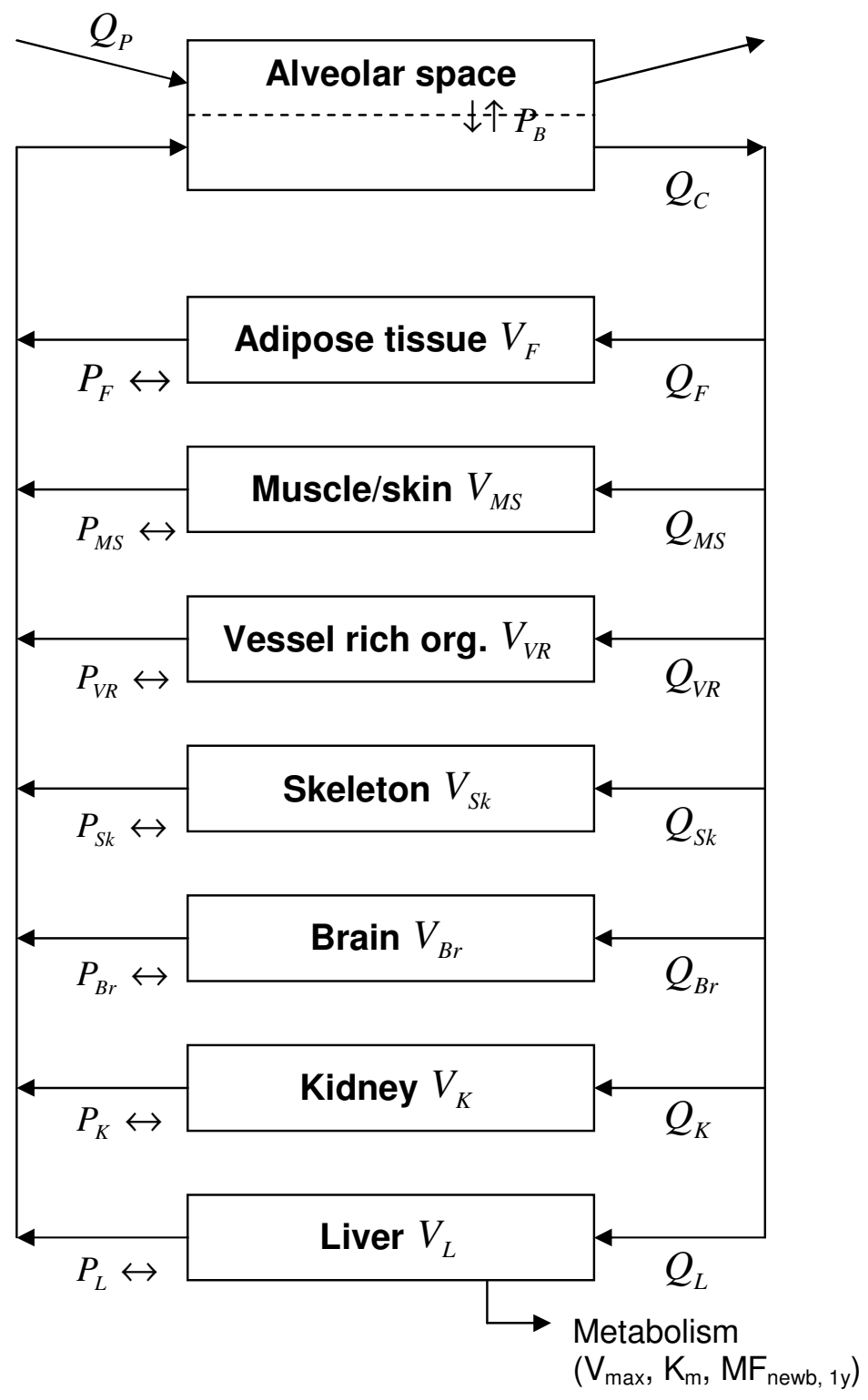


Figure $2 a$ and $2 b$

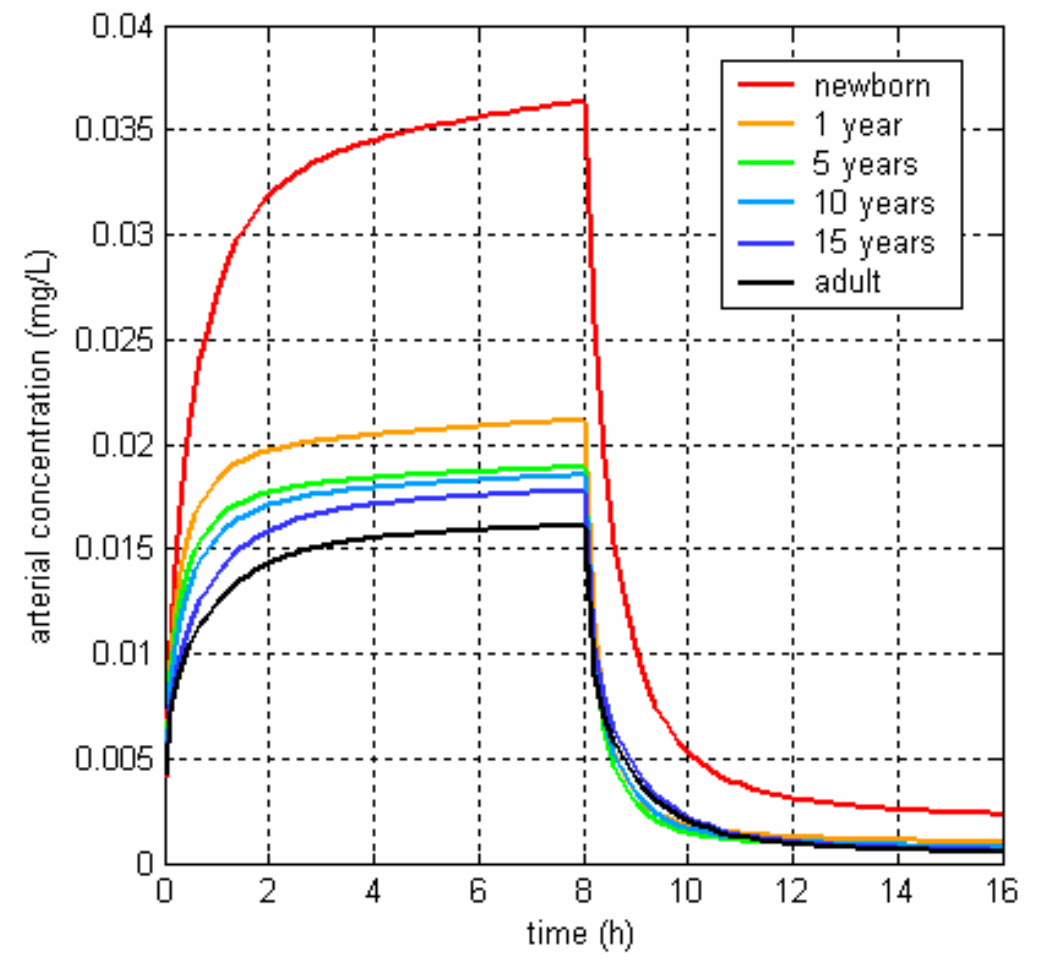

1 ppm

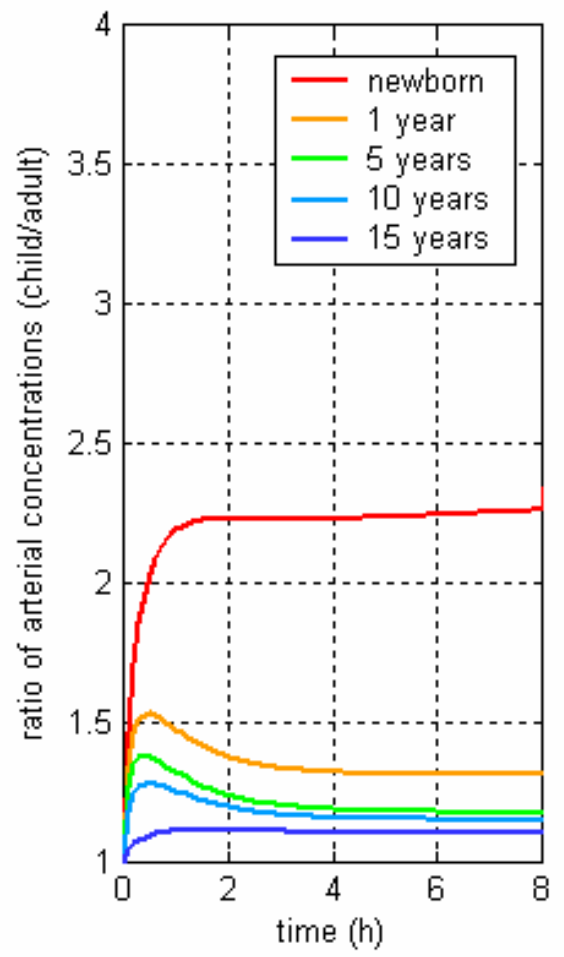




\section{Figure $3 a$ and $3 b$}

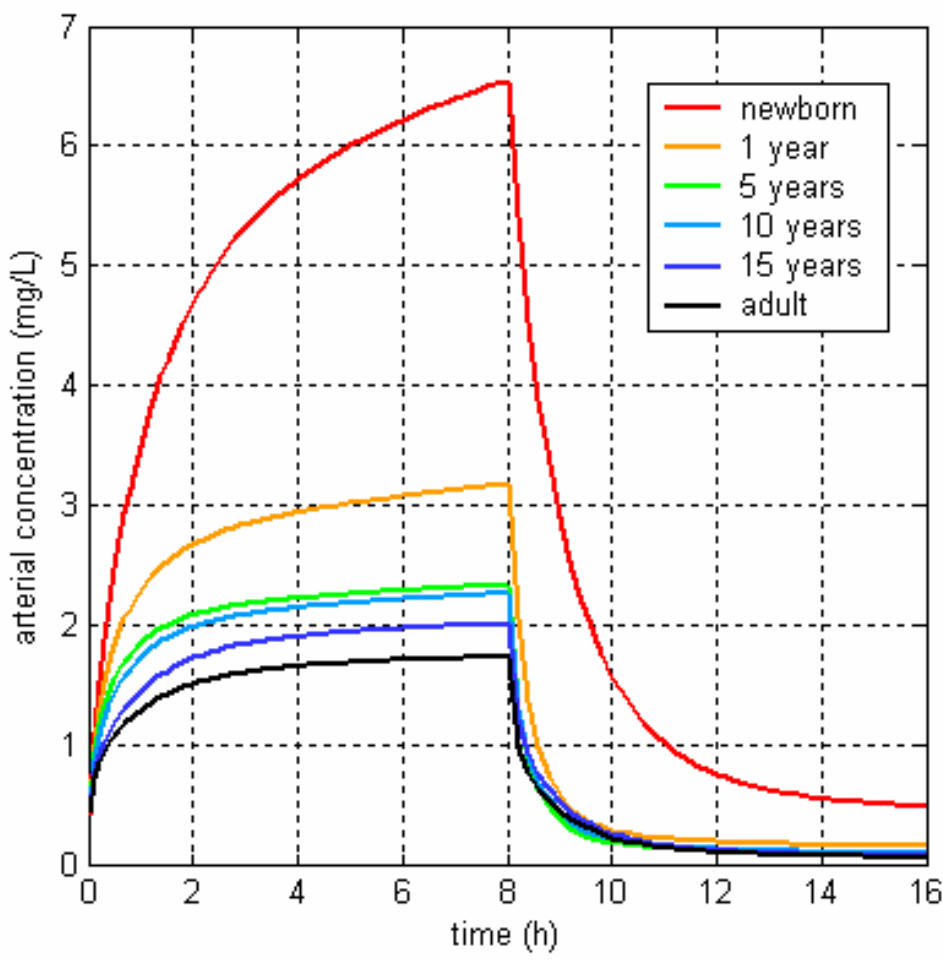

100 ppm

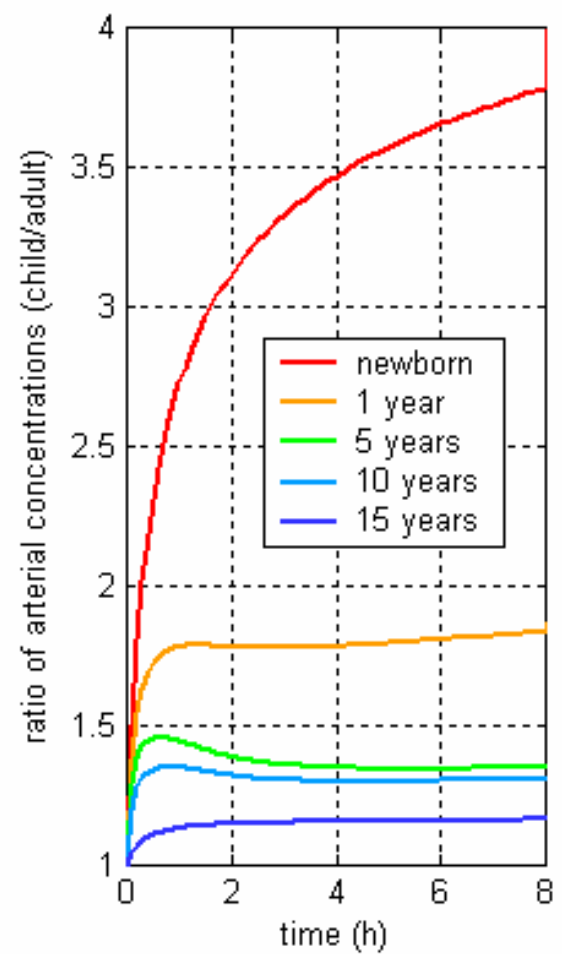




\section{Figure $4 a$ and $4 b$}
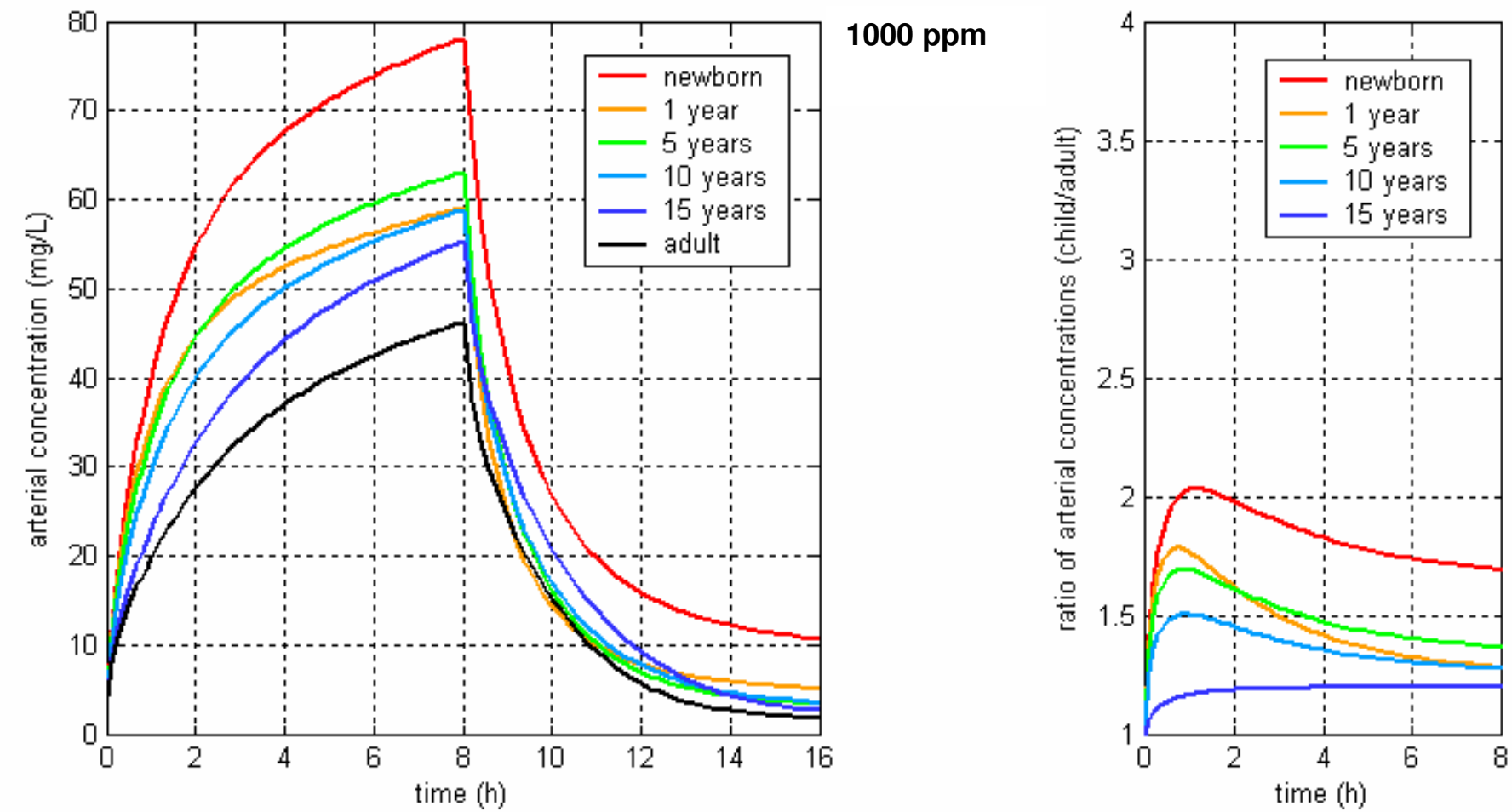
Figure 5

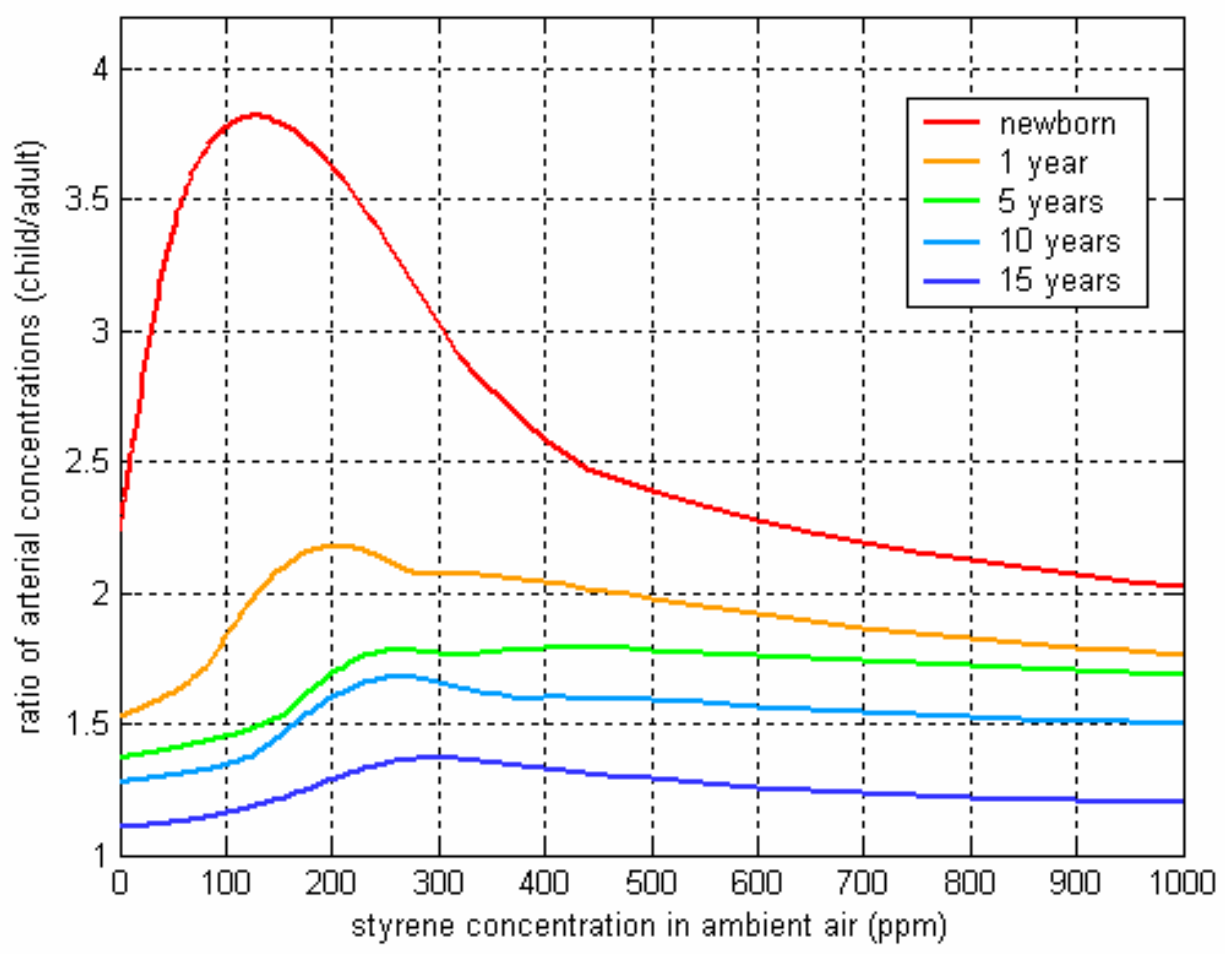


Figure $6 a$ and $b$

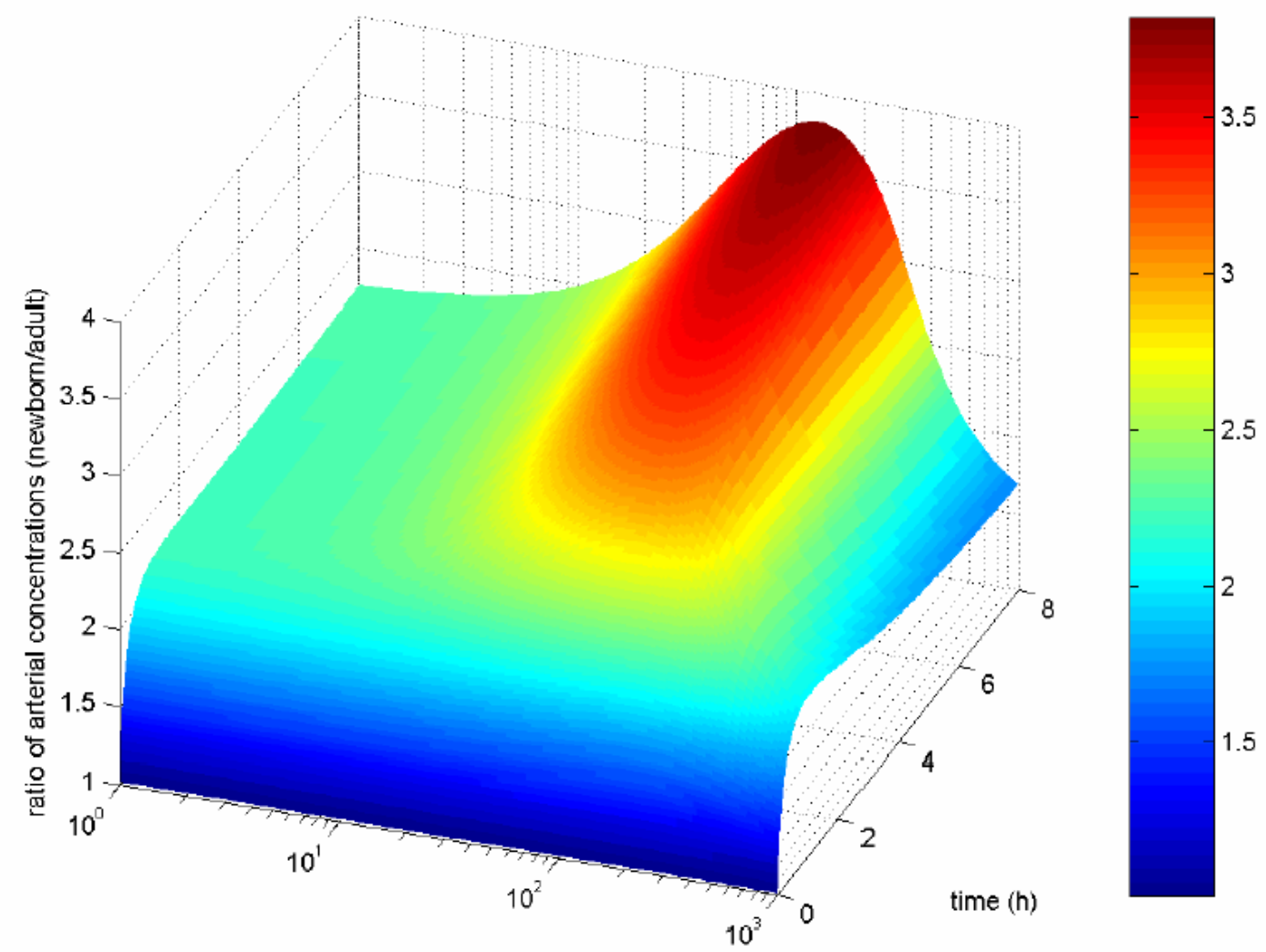

styrene concentration in ambient air (ppm)

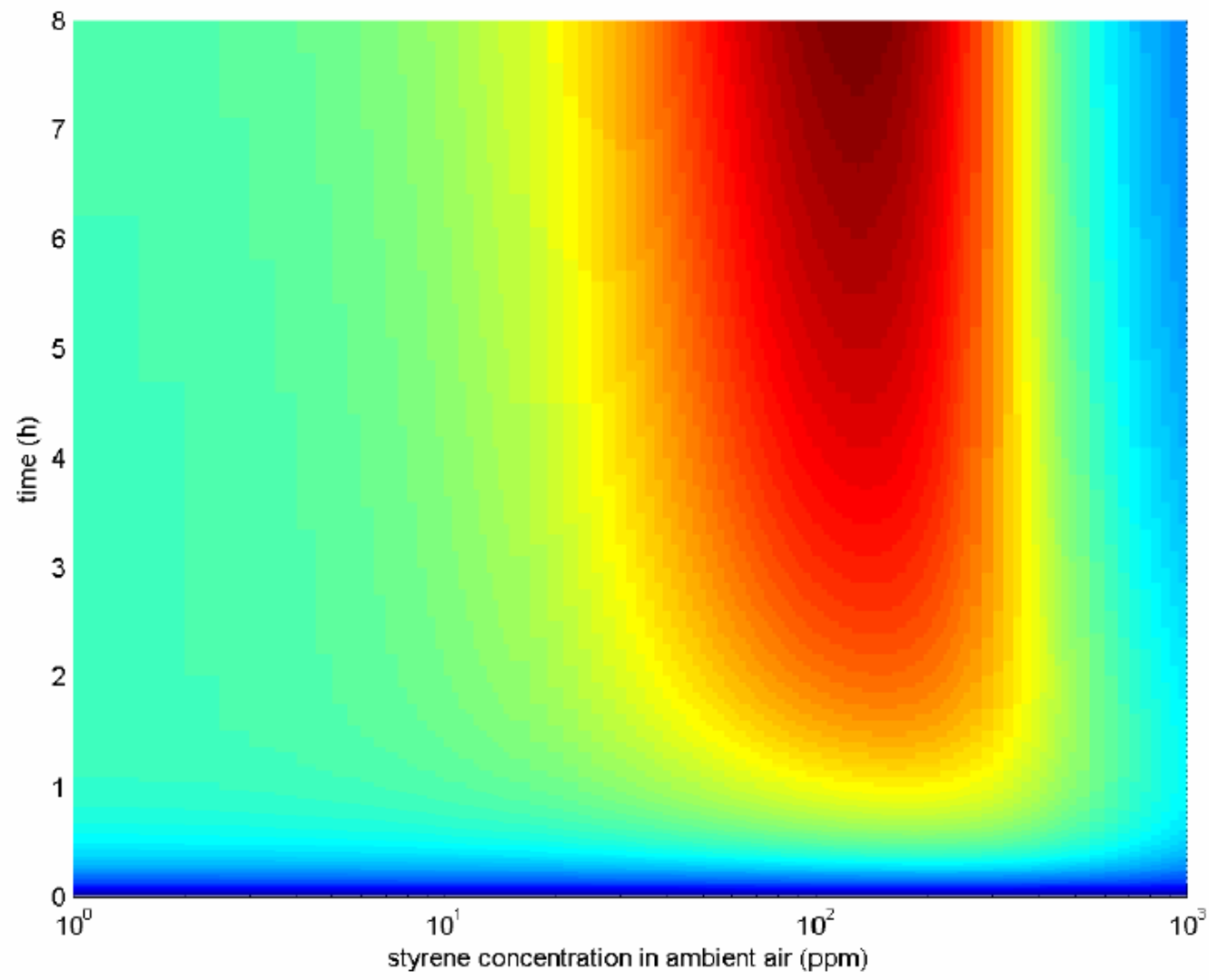

